\title{
Almost French: Food, Class, AND Gender in The American Expatriate Memoir
}

\author{
Malin Lidström Brock
}

\begin{abstract}
This chapter examines the significance of food references in three contemporary memoirs of life in France: Harriet Welty Rochefort's two memoirs French Toast: An American in Paris Celebrates the Maddening Mysteries of the French (1997) and French Fried: The Culinary Capers of an American in Paris (2001), and Suzy Gershman's C'est La Vie: An American Woman Begins a New Life in Paris and-Voila!-Becomes Almost French (2004). The two authors portray France as a place where individual Americans are able to live a richer, freer, and more authentic life than in the United States and, in the process, become a more sophisticated and fulfilled version of themselves. The argument made in this chapter is that this portrayal is both supported and contradicted by references to food. The references serve the double function of making the lifestyle in the memoirs seem at once accessible and inaccessible to readers. In the memoirs, the mastery of French cuisine and dining rituals are described as important steps in the two authors' inner journeys toward a more authentic sense of self. ${ }^{l}$ What they eat is presented as the result of a personal choice of moving to France, a reflection of their individual taste (Clark 32). At the same time, their food preferences are socially determined. Eating like the French, both authors argue, is to become "almost French" (Gershman 222; Rochefort, French Toast 105). ${ }^{2}$ French food culture, like French culture in general, is considered a "high context culture," that is, a culture strongly influenced by tradition and implicit rules (Hall 125-28). As pointed out by Priscilla P. Clark, "the more ritualistic the dining procedure, the more social and less individual the behavior
\end{abstract}


becomes, and the more potential individual anarchy is constrained by social imperatives" (32). In this respect, references to French cuisine in the memoirs contradict the authors' accounts of life in France as an escape from social constraints.

Food references are ubiquitous in memoirs of life in France, yet their significance to readers has received little scholarly attention. None of the three texts discussed in this chapter has previously been subjected to critical analysis. Studying the food references in these memoirs reveals that allusions to French cuisine result in hierarchical class and gender distinctions that are not made explicit, but they can still be easily identified by readers. Pierre Bourdieu's definition of taste as cultural capital helps to explain the memoirs' association of French cuisine with upper-class culture. The argument that American readers can identify the class aspects of the food references is supported by Priscilla Parkhurst Ferguson's historical study of French cuisine, Accounting for Taste: The Triumph of French Cuisine, which describes the facility by which the cuisine was exported internationally, and Patric Kuh's The Last Days of Haute Cuisine: America's Cultural Revolution, which traces the rise of French cuisine's status in the United States. Readers' identification of the gendered features of the memoirs is similarly corroborated by Catherine Manton's Fed Up: Women and Food in America, which considers the politicization of women's relationship to food. The gendered dimension of the food references is similarly underscored when viewed in the context of The Feminine Mystique, Betty Friedan's study of the 1960s suburban housewife ideal.

The lifestyle described by Rochefort and Gershman is clearly attractive to many readers. At the same time, the class and gender distinctions that the food descriptions convey risk causing an ideological gap between the memoirs as gendered stories of privilege and exclusivity, and contemporary American readers brought up on an ideology of class and gender equality. This latter ideology is best defined as democratic and meritocratic. It is founded on the popular idea of the United States as classless, multicultural, and equal when it comes to the individual's opportunity for "socioeconomic and cultural advancement, at least in theory" (Johnston and Baumann 172). ${ }^{3}$ The same food references, it will be argued in this chapter, reduce the stated ideological gap by making the privileged lives seem more palatable and accessible to readers. Highlighting the thematic and structural role that French cuisine plays in the three texts, the "democratic" aspects of the memoirs will become apparent. Rochefort's and Gershman's references to French cuisine serve as synecdoches for their 
expatriate experiences and for a lifestyle that is portrayed as highly individual, but also socially and culturally determined.

\section{The Personal Story as Lifestyle Guide}

The mention of food in their memoirs contributes to Rochefort's and Gershman's presentations of themselves as individuals who have made the personal choice of moving to France in pursuit of a more satisfying life. References to French cuisine are essential to this transformation narrative, although neither author has made a living from food in the manner of, for example, food writer M. F. K. Fisher or cookbook author Julia Child, who have both written memoirs about their time in France. ${ }^{4}$ Ostensibly about their personal lives, Gershman's and Rochefort's memoirs can simultaneously be read as cultural guides to France and to a lifestyle marketed by the authors as typically French. ${ }^{5}$ Access to good food is an important feature of this lifestyle. This emphasis on food, however, also brings to light the authors' unacknowledged class and gender assumptions that threaten to undermine the lifestyle's appeal to American readers.

Food has become a measure of self-worth, a means of self-definition. The relationship between food and identity has resulted in great concern about what we eat (Manton 82). Rochefort and Gershman refer to their love of France as a personal desire that defines who they are. This desire is often expressed as a love for French cuisine. Rochefort's two memoirs are organized thematically, but a chronology also emerges in the texts that traces the protagonist's increasing fascination with France and French culture. Growing up in Shenandoah, Iowa, in the 1960s, Rochefort forms an impression of France as "alluring," "romantic," and "crucially unfamiliar" (French Fried 12). ${ }^{6}$ As a student, she travels to Paris, where she has "a defining experience":

When you are twenty years old and emerge from the Midwest and a sheltered life... and find yourself in a simple hotel in the Latin Quarter overlooking the roofs of Paris... when you peer at the people and they look different, talk different, and act different...you might, like me, be so totally enthralled that you want to be those people, speak their language, eat their food, and drink their wine. (French Fried 14)

Rochefort's desire to imitate the French implies the profound effect the encounter with French culture has on her sense of self. In Paris 
she also meets Philippe, the Frenchman whom she eventually marries. What she learns from him and his family about the French and their habits forms the core of the memoirs. As a new bride in France, she establishes a relationship with her extended French family by learning how to cook in a typical French manner. "Catching on to French food," she explains, "was both easy and complicated. Easy because I had excellent teachers in my husband's family" (French Toast 9). Discovering what constitutes a proper meal to this family, learning to plan meals in courses, and mastering traditional family recipes are more complicated tasks that establish Rochefort's place in the new country, and satisfy her longing for a more cultivated life (9-12). The transformation seems complete when, in her second memoir, she states that she no longer eats French fries and refuses to make them at home, even though Philippe and their two half-French children love them. The implication is that after twenty years in France, Rochefort has become even more French than the French themselves; French fries are too unhealthy, too "American," to make it into her nowutterly French kitchen and life (French Fried 45-6).

Gershman's memoir differs in several respects from Rochefort's but similarly uses food references to illustrate the author's immersion in French culture and the effect it has on her sense of self. Gershman decides to move to Paris after Mike's, her husband's, death. In the memoir she recounts her experiences of discovering a new culture and trying to understand its rules. As the author of a series of international shopping guides, Gershman has visited Paris many times, but never lived there. By moving to France, she hopes for a different future than she envisions in the United States:

I was... seduced by a [French] lifestyle that seemed a lot more sophisticated than the long-range future I pictured for myself in the United States - bingo on Wednesdays, ... waiting for the chocolate pudding to be served. I knew I would never be rich so the French ideal of a small piece of life with good food, good friends and real butter seemed ... more attractive. (1-2)

Gershman's statement is an example of the metonymical function food has in her memoir. The "chocolate pudding" served in the retirement homes in the United States is certain to be preprocessed and tasteless, much like the future that Gershman wishes to avoid, contrary to the "real butter" and the life she imagines to share with good friends in France. Despite her general enthusiasm for French culture, Gershman initially expresses an ambivalent attitude to French 
cuisine, which hints at the difficulty she has in adjusting to her new surroundings. For example, she makes no attempt to increase her cooking repertoire by including French dishes. Instead, she eats in restaurants and cooks favorite American dishes using French products. To her, American food is comfort food, and reminds her of her husband and their life together, as she explains when describing her first Thanksgiving dinner in Paris: "I had brought cornbread stuffing mix, pumpkin pie mix, canned sweet potatoes and a huge bag of marshmallows...Food is comfort... I set the table for Mike and we left it empty" (234). Only toward the end of the memoir does she try out a few French recipes in her kitchen (250). This hands-on approach to French cuisine corresponds with a more accepting stage in her grieving process and an increasing familiarity with France. It also signifies a readiness to give up her cosmopolitan lifestyle in Paris for a house in Provence: "I had arrived with one notion of what was right for me, only to discover another way to get an equal, or better, result" (255). Gershman's rejection of her Parisian lifestyle suggests that it resembles her previous life too much. To satisfy a desire for authenticity, she retires to the less hectic countryside.

As residents in France, Rochefort and Gershman claim to have unique insights into the lifestyle they are describing. When they share these insights with their readers, it implies that this life is thereby made accessible to everyone. The view of France that the authors portray is well known, even clichéd. Both authors stress French people's appreciation of food and wine. Several of the chapters in Rochefort's memoirs are set in the family's large country house, "where there are always at least ten people at the table" (French Toast 9). "Like proper French citizens," Gershman tells us in her memoir, she and her friends sit at the dinner table "well into the night, [sipping] a little wine" (57) and having "real conversations" (120). Frenchwomen and their relationship to food are described in equally recognizable terms. In Rochefort's French family, the women embrace conventional notions of femininity. They cook in high-heeled shoes, and, to Rochefort's astonishment, never wear an apron (French Toast 10, 22). Gershman, who struggles to come to terms with her husband's death, expresses excitement at trying out variations of this role when she takes a French lover and goes on a diet in an attempt to feel, and look, more French (122-23). Rochefort, on her part, appreciates the free life that she identifies with France, such as "the lack of pressure to join groups.... Not being a joiner, I am grateful for this freedom" (French Toast 105). Although the authors present life in France as free from many of the 
constraints they believe characterize life in the United States, both argue that to thrive in France, one must learn to decipher the social and cultural codes that make life there seemingly impenetrable to outsiders. Indeed, for all their differences, the three memoirs are remarkably similar in this claim. What neither author talks of are the privilege and the gender prejudice that inform these codes. Signs of both are nevertheless detectable in the memoirs and risk alienating readers, who are otherwise attracted to the lives the authors portray. The most visible of these signs to an American readership appears in the authors' references to French cuisine.

\section{The Status of French Cuisine}

References to French cuisine in Rochefort's and Gershman's respective memoirs are not the only signs of the two authors' social status. Because of the privileged position that French cuisine has held in American twentieth-century culinary culture, however, these references are arguably the most identifiable markers of class to an American readership. While the word food typically refers to "the material substances consumed," Ferguson defines the word "cuisine" as a "cultural construct that systematizes culinary practices and transmutes the spontaneous culinary gesture into a stable cultural code" (3). An awareness of such codes constitutes what Pierre Bourdieu calls "cultural capital" in a society and helps to distinguish between social classes (177). By American readers, Rochefort's and Gershman's access to and appreciation of French cuisine can be understood precisely as such capital. To Bourdieu, cultural capital, together with social and economic capital, is indicative of social class (114). Cultural capital helps members of the same class to identify each other and to distance themselves from lower social groups. Such capital includes, for example, education, music preferences, where one vacations and how one organizes one's social space (70). When Rochefort describes her husband as a man, who was raised in the fifteenth arrondissement, attended a "grande école," has a doctoral degree in economics, likes to play the piano, and "is not at all hot for sports (either participating or observing)" (French Toast 3), she is also identifying Philippe as a member of the dominant classes in France (Bourdieu 114). How and where people do their grocery shopping; when and why they eat; and how people prepare, present, and socialize around their meals also constitute cultural capital (184-92). Ultimately, however, cultural 
capital must be understood as relational to other kinds of capital that Bourdieu identifies and its value will depend on the field, or social arena, in which a person is participating (101).

The tendency of American readers to identify French cuisine as a sign of high status has historical reasons. According to Ferguson, nineteenth-century French cuisine became influential internationally because it was heavily systematized and normative (71-2, 74). The formalization of cooking practices, the creation of an exact vocabulary, and a strict kitchen staff hierarchy meant that French cuisine could, at least in theory, be reproduced anywhere. At the same time, French cuisine remained closely associated with French regional cultures and with the development of the French nation itself (81). Wherever French cuisine traveled, so did notions of French culture, French history, and French geography (74). This migration of ideas took place when French cuisine was introduced in the United States (Kuh 12, 68). In French Fried, Rochefort offers an example of such migration when she describes the opening of Shenandoah's first French restaurant as a significant event in her childhood. Through this restaurant, she writes, "Shenandoahans [were] introduced to a touch of class" (10), and she contrasts the unconventional restaurant owners with their new midwestern surroundings by referring to the former as "exotic French birds in a sea of corn" (12). The high status accorded to French cuisine in Rochefort's memoirs can also be understood as a consequence of what Lawrence Levine calls the American "sacralization," or idealization, of European culture (85). The 1950s identification of French cuisine with American haute cuisine and White Anlgo-Saxon Protestant (WASP) upper-middleclass culture meant that French cuisine became highly interesting for Americans with social aspirations (Kuh 105-06). In the 1960s, Julia Child strove to decode French cuisine for the middle classes through her best-selling cookbook Mastering the Art of French Cooking and televised cooking shows. With her insistence on fresh produce and methodical cooking skills, Child challenged an American middleclass culture dominated by prepackaged and overprocessed foods (Kuh 104). Child showed that French cuisine could be reproduced in kitchens anywhere in United States, and with it came the promise of a different, more sophisticated, way of life. The sacralization of French cuisine may explain Gershman's initial attitude to French cooking: "When I first came to Paris, I did not have the gall (excuse the pun) to cook French" (250). French cuisine's ability to intimidate Gershman reveals the high status she accords both the cuisine and French culture in general. 
What and how we eat have come to stand for who we are. By contrasting French cuisine with American food habits, Rochefort and Gershman indirectly assert the superiority of their respective life choices. Although French cuisine no longer monopolizes American haute cuisine and food trends have become more "omnivorous," it has retained its status as cultural capital (Johnston and Baumann 167; Peterson and Kern 901). The reasons are not just historical, but the increasing popularity of farmers' markets and the food chains that mimic them, such as Whole Foods and Trader Joe's. Both phenomena illustrate a new, elitist food trend inspired by the so-called slow food movement. This is a movement that emphasizes "authentic," time-consuming dishes, made with organic ingredients and produced locally (Petrini 1-4). Many of the same qualities define classic French cuisine. In French Fried, Rochefort relies on this definition of French cuisine when she presents two lists of what Americans and French people supposedly find strange or unappetizing about each other's food habits. The list of French foods to which Rochefort claims Americans object includes - apart from the predictable snails and frog legs-items such as sea urchins, gizzard, offal, pig's feet, veal head, vinaigrette, and strong-smelling cheese (60-1). The list of objectionable American foods, from a supposedly French perspective, includes such items as Jell-O, coffee "(too weak)," overcooked meat, processed cheese, and American mustard "(too sweet)" (59-60). The contrast between Rochefort's two lists establishes a hierarchy of eating habits that favors the French and their cuisine, and consequently her own eating habits. The list of French items is twice as long as the American list, which suggests that the French are more adventurous in their eating habits. The impression is misleading, however, since the American list does not reflect the eating habits of Americans in general. Instead, it illustrates the food habits of the less food-conscious and poorest section of the American population. ${ }^{7}$ The French list, meanwhile, describes the tastes of a much wider section of the French population. Rochefort never addresses the socioeconomic discrepancy between the two lists, and as a consequence, the class distinction appears "natural," as if the French naturally have better taste than Americans, and the distance between the two countries' eating habits greater than might actually be the case. Of course, food items such as fois gras and gizzard may be unfamiliar or objectionable on ethical grounds to many American readers, who are otherwise attracted to the French lifestyle. Regardless, the distance Rochefort establishes both socially and culturally between France and the United States risks alienating many American readers by drawing attention to her memoirs' elitist 
connotations. It may seem like a paradox therefore that her references to French cuisine, which are largely responsible for the elitist impression, also serve to moderate these connotations.

French cuisine's double function in the memoirs, its ability to convey both high status and egalitarianism, becomes apparent when considering the recipes included in Rochefort's second memoir, French Fried. The inclusion of recipes in the memoirs serves a particular purpose; they offer an "exclusive" taste of France and simultaneously make the French lifestyle seem more accessible to readers. The recipes reassure readers that some aspects of the French lifestyle that Rochefort describes are available to everybody, or at least to readers whose "individual" taste leans toward a "natural" appreciation of French cuisine. The majority of the recipes are based on the less complicated dishes that make up this cuisine and rely on ingredients familiar to most Americans. They include, for example, onion soup, potato omelet, and several types of salad $(28-9,43,148-49) .{ }^{8}$ None of the recipes refers to any of the more complicated courses that Rochefort mentions in her text, such as "pied de porc au génepi, pig's foot with artemisia" (65), or "filet de biche sauce grand veneur, fillet of deer in a grand veneur sauce, [which] was delicious, even though the deer turned out to be a sanglier, boar" (81). In comparison, the "easy endive salad," for example, with only five ingredients-endives, Roquefort cheese, walnuts, bacon, and apples - and no actual cooking involved, is a very simple dish (102). At the same time, the simplicity of the recipes should not be mistaken for a lack of "authenticity." Historically, French cuisine has evolved from a combination of extravagant ancien régime cuisine and regional French cooking that relied on simplicity (Ferguson 46-7). Simplicity in French cuisine is a treasured quality that "implies a host of other qualities-harmony, elegance, and above all, that notoriously slippery quality, good taste" (68). ${ }^{9}$ Together with artisanal food products and food items associated with a particular place or individual(s), dishes grounded in traditional simplicity have come to be known as "authentic" (Johnston and Baumann 179-85). Simplicity_and by implication "authenticity" — defines the recipes in French Fried. Everyone cannot move to Paris and marry into a French family; most readers, on the other hand, can learn how to make vinaigrette, which only involves mixing mustard, vinegar, salt, pepper, and oil (French Fried 44). The recipes may be simple to reproduce but their very simplicity promises that the reader, too, can easily achieve an "almost French" lifestyle, if he or she should so wish.

The double function of Rochefort's references to French cuisine is likewise discernible in Gershman's memoir that does not include 
recipes but presents readers with a narrative that reads like an "education" in French taste. The autodidactic aspect of her memoir suggests that anyone can replicate her personal journey of improvement. In the memoir, a hierarchical distinction between American and French culinary cultures emerges from the plot. Gershman initially encounters French cuisine only in Michelin-starred restaurants, which suggests an unreachable, because expensive, lifestyle that involves connections with people of influence and importance in French society, such as "superchef Alain Ducasse" (88). Soon it emerges, however, that Gershman cannot afford this restaurant lifestyle. The reckless spending of the life insurance money from her late husband is described in detail in the memoir. At one point, she acknowledges that she has "spent almost $\$ 10,000$ to get the living room and dining area going. And this doesn't include dishes, cutlery or table linen" (71). The extravagant spending suggests a nouveau riche and consequently rather lowbrow attitude to money (Lamont $\mathrm{x}$ ). The "inauthenticity" of this lifestyle is illustrated by the prepackaged, overprocessed, "American" food that Gershman eats at home: "Brownies made from Betty Crocker brownie mix with a plop of crème fraîche on top ... chocolate batter from an American mix" (209). Like Rochefort, Gershman avoids describing these unhealthy "American" food habits in class-based terms. Instead, she explains them in psychological terms, as expressions of her grief.

By tracing her developing familiarity with French cuisine, Gershman establishes a covert link between French cuisine and class, yet still ensures her readers of the memoir's egalitarian character. Her story implies that immersion in French cuisine alone will have an overall positive effect on anyone's social status and sense of self. After six months of living in France, "suddenly meals and social life were the most important parts of my day. Yes, more important than my work... In the United States we rarely made time for our friends and the people we cared about" (119). Her earlier extravagant lifestyle is slowly replaced by a more "authentic," because simpler and less expensive, yet equally privileged, French lifestyle in the countryside, where food is mainly produced at home. The change serves as a reminder that cultural capital is distinct from economic capital (Bourdieu 66). That is, an appreciation of French cuisine can be understood as a sign of distinction in itself, apart from a person's financial situation. Gershman, however, remains financially privileged compared to many people. Toward the end of the memoir it is clear that she is still wealthy enough to afford a house in Provence. Despite the affluence suggested by this purchase, Gershman's personal transformation 
supports the idea that exposure to French cuisine alone will have a positive effect on an individual's quality of life. In this respect, it is significant that the first French dishes she makes at home are relatively simple desserts, such as a tarte tatin and shortly thereafter, a clafoutis. The simplicity of the dishes helps reassuring readers that they, in the same manner as Rochefort's readers, can achieve an "almost French" lifestyle through what they eat and in the comfort of their American homes. The link between food and class contributes to the memoirs' attraction for readers with social aspirations. At the same time, it complicates the authors' presentations of a French lifestyle as simply a matter of individual choice. The same holds true for the links that Gershman and Rochefort establish between women and food.

\section{Women and French Cuisine}

Life in France is especially conducive to women, according to Gershman and Rochefort. In France, both authors argue, women are free to express themselves through a love for food, which is not possible in the United States. Gershman describes how she used to eat before she moved to France: "I never had time to cook; my family survived on take-out, fast food, Boston Chicken and lamb chops on Sunday night" (119). Rochefort, on her part, seems to agree with French mothers-in-law who believe that "an American wife is always ... either poisoning her husband or allowing him to starve" (28); she admits that she did not know how to cook when she first arrived in France, because she had never learned to back in the United States. Since the French approach to food is described as positive and healthy, by implication, the United States becomes a place where women's relationship to food is guilt-ridden, politicized, and unhealthy. The positive view of women's relationship to food in France is contradicted, however, by Rochefort's and Gershman's observations of Frenchwomen, especially Parisian women, and their complex relationship to food. Ultimately, these observations reveal the unacknowledged gender prejudice that informs the connection Rochefort and Gershman make between women and French cuisine. This prejudice risks alienating American female readers schooled in gender awareness.

From the outset, Rochefort and Gershman seek to establish a positive connection between women and French cuisine. In French Toast, Rochefort dedicates two whole sections to the subject of women in France. In her opinion, "there is lightness in male-female 
relationships [in France] that we Anglo-Saxons don't always get" (36). This explains, she writes, why "French women spend a lot of time in the kitchen," but never complain (French Fried 32). "Food being a pleasure, I don't think anyone in France could imagine fighting about it" (32), she exclaims. On the contrary, she concludes, domestic control gives women in France a power in the relationship that American women lack (French Toast 4l). Gershman, too, stresses women's positive attitude to food in France. Her gradual immersion in French culture changes the way she eats and thinks about food. At the end of her memoir, she has finally taken control of her eating habits and no longer lives on junk food (250). This change imbues her with new confidence and a stronger sense of self: "Did I still need to buy a house to be French when I could master the tarte tatin" (250), she asks.

In a society where women are no longer focusing on themselves as a group with common interests but see themselves as individuals, the focus on healthy eating habits can be interpreted as a feminist act (McGee). The ability to prepare one's own food is a way for women to achieve control over their self-image (Manton 111). Cooking can also be understood as a creative act. Indeed, Julia Child, who introduced French cuisine to the American middle class, has been identified as "the feminist we will remember" for her "sensuality and delight" in cooking (Lydon 11). As a woman "at home in the world, entirely herself," she reminds Camille Paglia of "the 'pre-War feminists' like Amelia Earhart and Katherine Hepburn. That is, she followed her own cheerful, hardworking instincts along a path so original that she never seemed to be competing with anyone, least of all a man" (Paglia qtd. in Lydon 11). Child's sensual delight in cooking is a reminder that "food can symbolize the nurturance and love a woman feels towards others. Food can be a vehicle for the expression of one's sensuous nature" (Manton 5). Gershman and Rochefort express their attitude to cooking in pleasurable terms. The success of Gershman's baking inspires her to experiment with new flavors: "I began to wonder why I did not see more variations of tarte tatin in different bakeries or restaurants" (25l). When Rochefort's mother-in-law insists on washing the lettuce six times to remove any trace of sand, and her husband always adds something green on top of white food, such as parsley on potatoes, Rochefort interprets these acts as examples of the respect French people give to food and the perfection required when cooking in France (French Toast 13). The same acts demonstrate that cooking depends on all five senses; the three memoirs suggest that cooking in France is a deeply sensual experience. 
The memoirs can also be understood as nostalgic accounts. At the time of publication, both women were in their fifties. As young women in the United States, it is likely that they experienced women's relationship to food similarly, even if one considers their distinct religious affiliations. ${ }^{10}$ Rochefort's and Gershman's accounts of women's relationship to food in France might be nostalgic longings for the 1950s and the 1960s, a time when American women's relationship to food was, supposedly, less neurotic and guilt-ridden than how the authors perceive it to be today. Such nostalgia nevertheless contradicts the positive link that the two authors seek to establish between women and food. American middle-class women of the 1950s and the 1960s were not expected to work outside the home once married, but "to remain sexually alluring to their husbands, while at the same time, to develop social skills that furthered their husbands' careers" (Manton 3). These social skills included cooking and entertaining at home. Betty Friedan famously referred to this ideal as "the feminine mystique" - an ideal that she believed made women severely unhappy and depressed (Friedan 15). The similarities between the unhappy housewife and the female ideal presented in Gershman's and Rochefort's respective memoirs challenge the two author's description of France as a country where women are free to realize their dreams and themselves through French cuisine.

From a feminist perspective that views the personal as political, the two authors' comments on Frenchwomen and their relationship to food are equally problematic. Rochefort complains that women in Paris are "unsisterly" and competitive with other women for male attention, and she criticizes their perfectionism (French Toast 23-4). A woman in Paris, she points out, is "invariably not only slim and wellcoiffed, with perfect nails, but she has also done an unbeatable job of preparing the meal" (21). The comment indicates that competence in the kitchen, the perfection Rochefort admires elsewhere in her memoirs, is more a social requirement for Frenchwomen than a source of personal joy. Gershman's personal experiences confirm the social pressure women feel in France. ${ }^{11}$ As she embarks on the affair with a married count, she consciously assigns herself the role of "mistress," a word that she associates with Frenchwomen in general: "I thought adultery was a French treat I should try out like Krug or courgette flowers" (142-43). Gershman decides to end the affair, however, when she realizes that it is conducted entirely on the count's terms. Later at a Christmas party, she encounters a man, who claims that he knows "everything there is to know about a woman ... because I am a Frenchman" (242). Her immediate reaction is: “No, I wanted to say, 
you are an asshole" (242). The silent reply suggests disillusionment with Gallic gallantry and the Frenchwoman as a female role model.

Neither author reflects on Frenchwomen's relationship to cooking in political terms. Indeed, they explicitly dismiss a feminist interpretative paradigm (French Toast 40; Gershman 31). When their general observations about women's situation in France are taken into account, however, the result is a perspective on Frenchwomen's relationship to food that opposes the two authors' expressed opinions on the subject. Rochefort defines France as a chauvinistic country, and observes that women are underrepresented in the National Assembly (French Toast 31). Frenchwomen's domestic chores, which include cooking, appear less attractive or powerful when considered in the context of statistics that show that over 80 percent of Frenchwomen between the ages of twenty-five to fifty-five are working outside the home (Bennhold, "Where Having It All Doesn't Mean Having Equality" A4). Taking into account their domestic responsibilities, the figure above reveals that women in France are working more than women in many other Western countries, not less. The conclusion undermines the two authors' presentation of France as an ideal place for women who wish to escape their hectic lifestyle (Gershman 129-30). Frenchwomen's relationship to French cuisine also seems less liberating or creative considering that most haute cuisine chefs in France are men. In an interview for The New York Times, Christine Lagarde, the then French minister of finance, mentions the glass ceiling for women in corporate France: "It's a bit like the good food we're eating and yet we manage not to be so overweight. Something of the same nature, right? Where we have conditions of equality, so to speak, yet it seems that women do not reach the top" (Bennhold, "Female Factor"). Lagarde's comment suggests that Frenchwomen's absence in the professional kitchen may not be a consequence of individual choice, but a reflection of systematic workplace inequality.

Regardless of problematic gender prejudice in Rochefort's and Gershman's memoirs, it must be kept in mind that their readers are mainly Americans, who will not move to France in search of a better lifestyle. Instead, they are likely to remain in the United States. As argued in this chapter, the life described in the memoirs gains its appeal from appearing at once accessible and inaccessible to readers. As a result, the memoirs can simultaneously inspire female readers and confirm their existing life choices no matter where these readers reside. If the reader agrees with the authors that American society undermines women's healthy relationship to food, the memoirs' link between women and French cuisine allows her to distinguish herself 
positively from her surroundings simply through her eating habits. At the same time, the formality and status associated with French cuisine add both structure and social prestige to these habits.

Rochefort's and Gershman's respective memoirs are personal accounts of life in Paris and guides to French culture. In their presentations of France as a place for self-realization, they are relying on unacknowledged class and gender assumptions. These assumptions risk alienating American readers, who might object to the elitist and sexist dimensions of the life described. In this respect, food descriptions play an important role in the two authors' presentation of France. References to French cuisine highlight the status and exclusivity of the French lifestyle, yet they also serve to make the memoirs more accessible to readers. The inclusion of recipes in Rochefort's memoirs indicates to the reader that he, or she, too, can live an "almost French" lifestyle back in the United States. On her part, Gershman's self-portrayal conveys the impression that a person's taste and social status are not only related but may also be subject to change. Although Frenchwomen are described as having a complicated relationship to food, at least partly from living in a society defined by inequality between the sexes, Rochefort's and Gershman's references to French cuisine suggest that female readers in the United States may still benefit from replicating an "almost French" lifestyle at home. Learning to master French cuisine, the memoirs imply, is both a self-defining and sensual experience.

\section{Notes}

1. In this chapter, cuisine refers to a system that "turns the private into the public, the singular into the collective, the material into the cultural...As cooking makes food fit to eat, so cuisine... turns the act of nourishment into an object fit for intellectual consumption" (Ferguson 3).

2. Henceforth French Toast is used as a short title for French Toast: An American in Paris Celebrates the Maddening Mysteries of the French.

3. See also Lamont (78-9).

4. See M. F. K. Fisher's The Gastronomical Me, first published in 1943, and Julia Child and Alex Prud'homme's My Life in France (2006).

5. Indeed, none of the memoirs is genre-listed or category-listed as "Memoir" or "Auto/biography," but rather as "[author's name]— Homes and haunts-France-Paris" and "France-social life and customs." Only French Toast: An American in Paris Celebrates the Maddening Mysteries of the French is categorized, in place number 4, as "Americans-France-Paris-Biography." Nevertheless, since the "vital statistics" of the author are identical to those of the narrator in each text, 
an "autobiographical pact" is made with the reader. The pact allows the reader to read the memoirs differently from fiction, and to approach them as vestiges of truth (Lejeune 21).

6. Henceforth French Fried is used as the short title for French Fried: The Culinary Capers of an American in Paris.

7. Lisa Miller reports a statement from the US Department of Agriculture: "17 percent of Americans-more than 50 million people-live in households that are "food insecure, a term that means a family sometimes runs out of money to buy food, or it sometimes runs out of food before it can get more money... what you eat for dinner has become the definitive marker of social status; as the distance between rich and poor continues to grow, the freshest, most nutritious foods have become luxury goods that only some can afford" (Miller).

8. Some of the recipes in the memoir are personalized by Rochefort, such as her "false" mayonnaise, thereby breaking with the normative structure of traditional French cuisine.

9. Ferguson credits Marie-Antoine Carême (1783-1833) as inventor of what came to be known as French cuisine in the nineteenth-century, and she observes that "many of our own culinary preferences are already present in his endeavors-the importance of seasonal products, the dominance of natural aromas. Carême's [French] cuisine sounds remarkably appropriate for the twenty-first century" (68).

10. Gershman identifies herself as Jewish (135) and Rochefort as Protestant (French Fried 8).

11. According to Catherina Manton, the demands on middle-class American housewives in the 1950s also imposed restrictions on the acceptable size of their bodies (3). Her observation casts new light on the image of the eternally slim Frenchwoman. The Frenchwoman's tendency to "joyfully accept everything but take miniscule portions" can be understood as a necessary consequence of living in a male-dominated society (French Toast 22). According to recent statistics, Frenchwomen are among the highest consumers of antidepressants in the world (Bennhold, "Where Having It All Doesn't Mean Having Equality").

\section{WORKS Cited}

Bennhold, Katrin. "Female Factor." www.nytimes.com. New York Times. Oct. 11, 2010. Web. Jan. 5, 2012.

- "Where Having It All Doesn't Mean Having Equality." www .nytimes.com. New York Times. A4. Oct. 12, 2010. Web. Jan. 5, 2012.

Bourdieu, Pierre. Distinction: A Social Critique of the Judgement of Taste. Translated by Richard Nice. New York: Routledge, 2006. Print.

Child, Julia and Alex Prud'homme. My Life in France. New York: Anchor, 2006. Print.

Child, Julia, Louisette Bertholle, and Simone Beck. Mastering the Art of French Cooking. 2 vols. New York: Penguin, 2009. Print. 
Clark, Priscilla P. "Thoughts for Food, I: French Cuisine and French Culture." The French Review 49.1 (1975): 32-41. Print.

Ferguson, Priscilla Parkhurst. Accounting for Taste: The Triumph of French Cuisine. Chicago: U of Chicago P, 2006. Print.

Fisher, M. F. K. The Gastronomical Me. New York: North Point, 1989. Print.

Friedan, Betty. The Feminine Mystique. New York: Norton, 1963. Print.

Gershman, Suzy. C'est La Vie: An American Woman Begins a New Life in Paris and-Voila!-Becomes Almost French. New York: Penguin, 2004. Print.

Hall, Edward T. Beyond Culture. New York: Random, 1989. Print.

Johnston, Josée and Shyon Baumann. "Democracy versus Distinction: Omnivorousness in Gourmet Food Writing." American Journal of Sociology 113.1 (2007): 165-204. Print.

Kuh, Patric. The Last Days of Haute Cuisine: America's Cultural Revolution. New York: Viking, 2001. Print.

Lamont, Michèle. Money, Morals, and Manners: The Culture of the French and American Upper-Middle Class. Chicago: U of Chicago P, 1994. Print.

Lejeune, Philippe. On Autobiography. Edited by Paul John Eakin, translated by Katherine Leary. Minneapolis: U of Minnesota P, 1989. Print.

Levine, Lawrence. Highbrow/Lowbrow: The Emergence of Cultural Hierarchy in America. Cambridge, MA: Harvard UP, 1990. Print.

Lydon, Christopher. "The Feminist We'll Remember." The Improper Bostonian. Mar.-Apr., 1996: 11-6. Feb. 11, 2012. Web. Jan. 6, 2012.

Manton, Catherine. Fed Up: Women and Food in America. Westport, CT: Bergin \& Garvey, 1999. Print.

McGee, Micki. Self-Help Inc.: Makeover Culture in American Life. New York: Oxford UP, 2005. Print.

Miller, Liza. "Divided We Eat." www.thedailybeast.com. The Daily Beast. Nov. 11, 2010. Web. Jan. 26, 2012.

Peterson, Richard A. and Roger M. Kern. "Changing Highbrow Taste: From Snob to Omnivore." American Sociological Review 61.5 (1996): 900-07. Print.

Petrini, Carlo. Slow Food: The Case for Taste. Translated by William McCuaig. New York: Columbia UP, 2001. Print.

Rochefort, Harriet Welty. French Fried: The Culinary Capers of an American in Paris. New York: St. Martin's, 2001. Print.

- French Toast: An American in Paris Celebrates the Maddening Mysteries of the French. New York: St. Martin's, 1997. Print. 
